\title{
Fabrication of Al-11.2Si Components by Direct Laser Metal Deposition for Automotive Applications
}

\author{
Amrinder Singh*, Abhishek Ramakrishnan*, and Guru Dinda*, ${ }^{*}$ \\ *Dept. of Mechanical Engineering, Wayne State University, Detroit, 48202, USA \\ †Corresponding author : dinda@wayne.edu \\ (Received April 27, 2017 ; Revised May 15, 2017 ; Accepted May 19, 2017)
}

\begin{abstract}
Recently, Al-Si alloys samples have been manufactured at lab scale using various additive manufacturing processes, but so far there is no literature available to investigate the feasibility of fabricating Al-Si alloy component for automotive component applications using Direct Laser Metal Deposition (LMD) technique. This paper deals with the practical challenges of building single wall and block deposition (cuboid shapes) of eutectic Al-Si alloy using direct laser metal deposition process for developing automotive applications. Two scanning pattern, hatch pattern and single wall pattern were chosen to study the effect of scanning direction on mechanical properties as well as microstructural evolution. Microstructural investigation of single wall and block deposition using optical and scanning electron microscopy revealed a $99.9 \%$ dense component with very fine hypoeutectic microstructure. Tensile test sample extracted from block deposition showed an impressive elongation of $9 \%$ with an ultimate tensile strength of $225 \mathrm{MPa}$ and tensile test sample of single wall showed an average elongation of $9.4 \%$ with an ultimate tensile strength of $225 \mathrm{MPa}$. This investigation revealed that direct laser metal deposition could successfully print the eutectic Al-Si alloy bracket on shock tower hood without any distortion or bending.
\end{abstract}

Key Words : Al-Si alloy, Laser cladding, Microstructure, Additive manufacturing, Laser metal deposition

\section{Introduction}

In current era, casted components of Al-Si alloy is being used from low load automotive part to high load engine parts because of sound castability and high corrosion resistance. Laser metal deposition of automotive parts will give not only design freedom but also an opportunity to eliminate joining time. The Additive Manufacturing (AM) of eutectic Al-Si alloy has received a special attention in last couple of years because of its endless applications in automotive and other sectors. Numerous studies shows that various additive manufacturing techniques had been able to successfully manufacture the Al-Si alloy parts but none of them had attempted to deposit Al-Si alloy on as-casted automotive parts. The scope and practical hurdles of practically implementing AM of Al-Si alloy ${ }^{1-5)}$ has not been studied in detail. The practical challenges involved in the laser additive manufacturing of Al-11.2Si alloy is discussed in the current study using systematic step by step approach from deposition of Al-11.2Si alloy on substrate to deposition on as-casted part. Tensile strength has been reported extensively for parts additively manufactured by powder bed fusion technology but to best of our knowledge, tensile strength of parts additively manufactured by laser metal deposition (LMD) has not been reported so far in open literature. LMD blend laser cladding with rapid prototyping, which provides full flexibility to manufacture any complex shape. Since the previous layer melts in LMD process and when new layers are added to previously partially melted layer, this helps in making a strong bond due to efficient fusion at interface. Hence Al-Si alloy parts can be printed on Al-Si casted parts with good bonding without any additional joining process. This systematic study shows the reliability and quality of the LMD process for Al-Si alloy deposition on as-casted Al-Si parts. Highly dense parts (99.9 percent) of Al-Si alloy have been achieved using LMD process in contrast to the sintering process 
(99.5 percent demonstrated by Thijs et al. $\left.{ }^{6}\right)$. Currently in automotive industry, either the parts are casted or press fit and then joined using numerous welding techniques. LMD can solve the problem of joining by printing components right on to the as-casted parts which will not only saves the time for joining but also provide design freedom. Current study deals with the implantation of printing automotive part on as-casted parts. LMD is not only limited to manufacturing but also can be used for remanufacturing, surface coating, repair etc. ${ }^{7-11)}$. In open literature, few reports demonstrated mechanical test results by Kang et al. ${ }^{12)}$, Wang et al. ${ }^{5)}$, Prakshanthet al. ${ }^{13)}$ and $\mathrm{Li}$ et al. ${ }^{14)}$ using selective laser sintering technique (SLS). Although Al-Si alloy has been successfully deposited in past using $\operatorname{SLS}^{1-6,15,16)}$ but to best of our knowldge no mechanical test has been reported using direct metal laser deposition in open literature.

\section{Experimental procedures}

Direct Laser Metal Deposition (LMD) process developed at Wayne State University has four main components: ABB six axis Robot, $2 \mathrm{KW}$ Diode laser, Powder feeder, Coaxial nozzle. LMD technology blends rapid prototyping with laser cladding to fabricate any part from cad model as shown in Fig. 2. The bottom part of nozzle assembly, which is attached at the end of robotic arm, is made from copper and have all the delivery holes as shown in Fig. 2(c) to deliver powder, nozzle
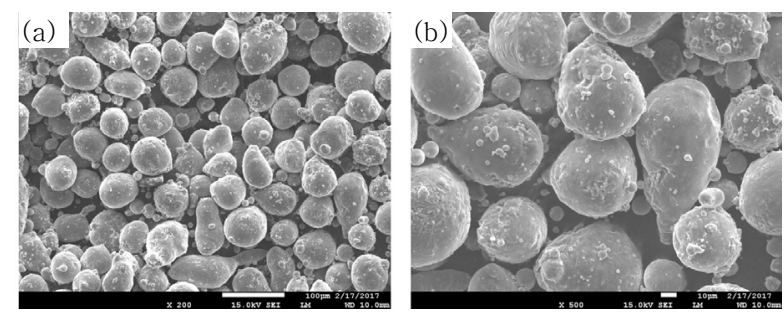

Fig. 1 (a) SEM image of as-received Al-11.2Si powder, (b) Zoomed view of alloy powder
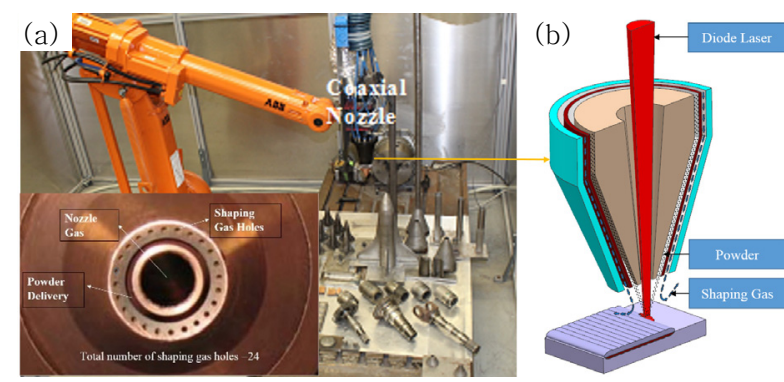

Fig. 2 (a) Nozzle attached at the end of robotic arm, (b) Schematic of laser metal deposition, (c) Nozzle bottom view showing powder and gas delivery holes gas, and shaping gas. Robot is programmed with two different scanning patterns in current study, hatch and single wall pattern as schematically shown in Fig. 4 for block and single wall deposition, respectively. Inside the nozzle, the coolant from chiller is circulated to avoid the nozzle damage by intense heat produced by the laser. Powder is rushed through nozzle powder delivery holes using powder hopper and shaping gas helps the powder to focus on the substrate. Laser focusing lens is protected by another protective lens, which is shielded using nozzle gas from powder dust and vapors. Since the preceding layer is partially melted and incoming powder also melts simultaneously which results in highly dense deposit and good bonding at every layer interface.

Valimet Inc supplied the gas atomized Al-Si alloy powder. The powder mesh size was within the range of $-100 /+325$. The morphology of powder is shown in Fig. 1. The powder particles were rather spherical, some having satellite powder particles as shown in magnified view in Fig. 1b. The composition of the as-received powder is shown in table 1 . The Al 6061 rolled plate was used as substrate material on which initial coupons were deposited to optimize the process parameters before replicating the bracket on shock tower hood. Laser metal deposition parameters: laser power, scanning velocity and powder feed rate were optimized to achieve defect free deposition of Al-Si alloy. The required laser power to melt Al-Si alloy is greater than other alloys such as Ni-, Fe- and Co-alloys, although Al alloys melting point is substantially lower than Ni-, Fe- and Co-alloys, because $\mathrm{Al}$ alloys have high thermal conductivity. The scanning velocity and powder flow rate was coupled to achieve a stable melt pool. Due to high thermal conductivity of $\mathrm{Al}$ alloys, the melt pool can be unstable if above mentioned process parameters are not optimized. As a result, the process window for $\mathrm{Al}$ alloy processing is rather narrow compared to the conventional alloys.

Standoff height (distance between nozzle bottom and layer being deposited) should be constant all the time to obtain the defect free deposition, which is hard to achieve in Al-Si alloys. The primary motive of this study is to print Al-Si alloy bracket on as-cast automotive cast part using direct metal laser deposition. A shock tower hood was chosen for demonstrating the deposition of Al-Si alloy. On this particular cast automotive component, there is lot of small components (e.g. bracket) that are casted separately and then joined back on the shock tower hood using spot welding. If we can directly deposit on the cast shock tower hood, joining time and cost would be a big saving. However, before start printing on the shock tower hood, a systematic study was conducted from microstructural analysis to mechanical testing on the Al-Si alloy deposited on the substrate. 

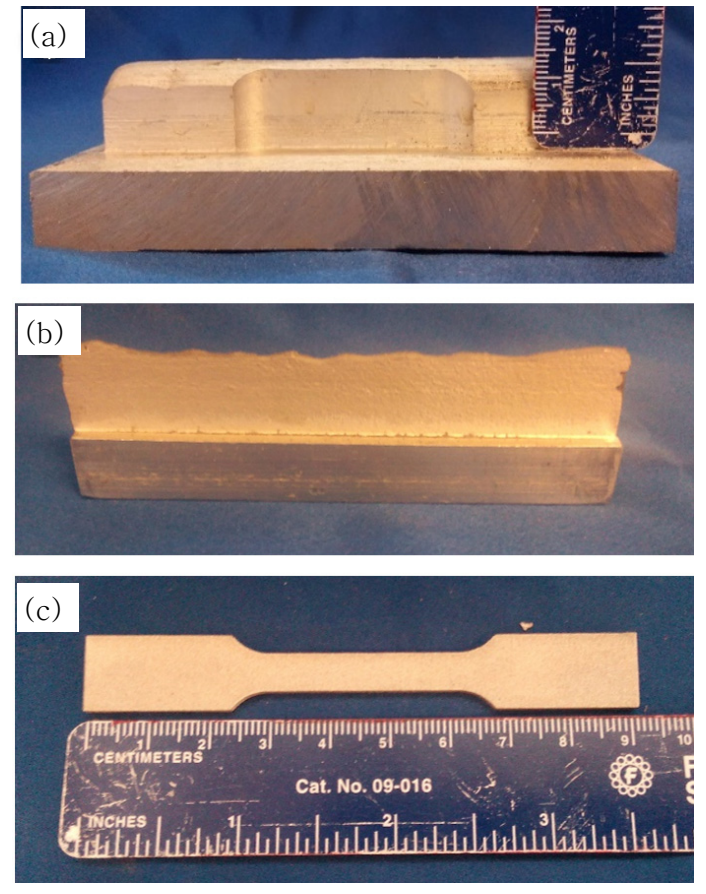

Fig. 3 (a) Block deposit milled to dog bone shape as per ASTM E8 standard, (b) Single wall deposit milled on both sides, (c) Final tensile sample

Using the optimized LMD parameters, Al-Si block of dimensions $(100 \mathrm{~mm} \times 17 \mathrm{~mm} \times 15 \mathrm{~mm})$ was used to prepare tensile test sample as shown in Fig. $3 \mathrm{a}$ and single wall deposition as shown in Fig. 3b. These tensile test samples were machined as per ASTM E8 standard dimensions. Dog bone shaped block was milled as shown in Fig. 3a. Wire EDM was used to slice out three tensile test samples of $2 \mathrm{~mm}$ thickness from dog bone shaped block. Three single wall deposits were made to mill three more tensile test samples. The primary objective of preparing samples from single wall and block was to investigate the effect of scanning pattern on mechanical properties. Moreover, the bracket on the shock tower is a single wall structure, so it was necessary to study the mechanical and microstructural properties of single wall deposition. Tensile test was performed using MTS 810 tensile testing machine for both single wall and block tensile test samples. Constant test speed of $0.05 \mathrm{~mm} / \mathrm{s}$ was maintained during the tensile test.

Detailed microstructural evolution was studied in both single wall and block deposit using optical and scanning electron microscopy (JSM 7600). Single wall detailed microstructural evolution is well studied and reported by Dinda et al. ${ }^{6}$. While depositing single wall, Powder feeder and laser were always active during the whole deposition period. Successive layer height increment of $0.4 \mathrm{~mm}$ was kept constant for both block and single wall deposition. A solution of $100 \mathrm{ml} \mathrm{H}_{2} \mathrm{O}, 25 \mathrm{ml} \mathrm{HNO}_{3}$, $15 \mathrm{ml} \mathrm{HCl}$, and $10 \mathrm{ml} \mathrm{Hf}$ was prepared to etch the met- allographic samples by dipping samples in for 10-12 seconds. XRD analysis was carried out on the polished flat top surface of deposit using Bruker D8 analyzer to identify various phases in the as-deposited samples and powder. Microhardness test was carried out using 100 gm load for dwell time of $10 \mathrm{~s}$ using Instron microhardness tester.

\section{Results and Discussion}

Direct laser metal deposition can be used to manufacture either a solid or a hollow part. Hollow part can be considered as thin wall structure with particular shape. So given these two scenarios, block and single wall deposition was carried out to investigate microstructure and mechanical properties before implementing the technique to shock tower hood (automotive part).

\subsection{Block deposition}

Block deposition was carried out using hatch pattern as shown in Fig. 4a. Two blocks with dimensions, $20 \mathrm{~mm} \times$ $20 \mathrm{~mm} \times 3 \mathrm{~mm}$ and $100 \mathrm{~mm} \times 17 \mathrm{~mm} \times 15 \mathrm{~mm}$ were deposited on a rolled Al-6061 substrate. The smaller block $(20 \mathrm{~mm} \times 20 \mathrm{~mm} \times 3 \mathrm{~mm}$ ) was cut into two equal halves and used for microscopy analysis. Optical micrographs confirmed the density of block deposition was greater than $99.9 \%$. The bigger block was used to make tensile sample. Tensile test exhibited excellent combination of elongation $(9 \%)$ and ultimate tensile strength

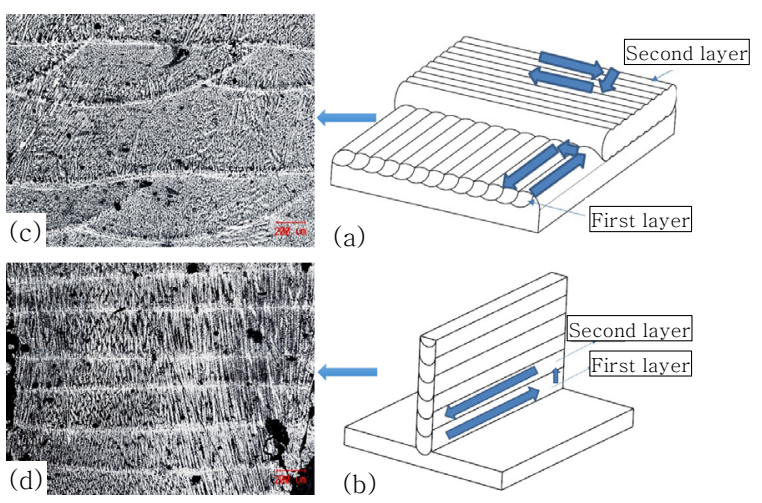

Fig. 4 (a) Block deposit scanning pattern, (b) Single wall deposit scanning pattern, (c) Block sample optical micrograph, (d) Single wall sample optical micrograph

Table 1 As-received Al-Si (S20) alloy composition

\begin{tabular}{|c|c|c|}
\hline $\mathrm{Si}$ & $\mathrm{Fe}$ & $\mathrm{Al}$ \\
\hline 11.18 & 0.15 & 88.65 \\
\hline
\end{tabular}


(225.7 MPa) as shown in Fig. 5, which is comparable with conventional cast component. Mechanical properties achieved through direct laser metal deposition process is comparable with the combination (Elongation \& UTS) achieved through selective laser sintered samples as per reported in available literature ${ }^{12,13)}$. Hence, results showed that deposition with no major defect is possible with mechanical properties at par with conventional properties. Table 2 shows the LMD optimized parameters. The powder feed rate was kept less $(2.6 \mathrm{~g} / \mathrm{min})$ in the very first deposited layer to achieve good bond with the substrate. The laser power particularly was constantly very high (900 Watt) in case of block deposition to attain the continuous melt pool because aluminum alloys have high thermal conductivity. Block deposition samples showed very consistent stress strain results as shown in Fig. 5, which points towards the isotropic properties. Hence, the hatch pattern provides the uniform properties of Al-Si alloy deposit across the height of block.

In case of block deposition, there is continuous pattern of alternate layer of overlapping bead like structure as shown in Fig. 4c. This unique microstructure pattern was a result of hatch scanning. In hatch scanning pattern, circular overlapping beads was observed in the first layer as shown in $4 \mathrm{c}$, second layer was deposited

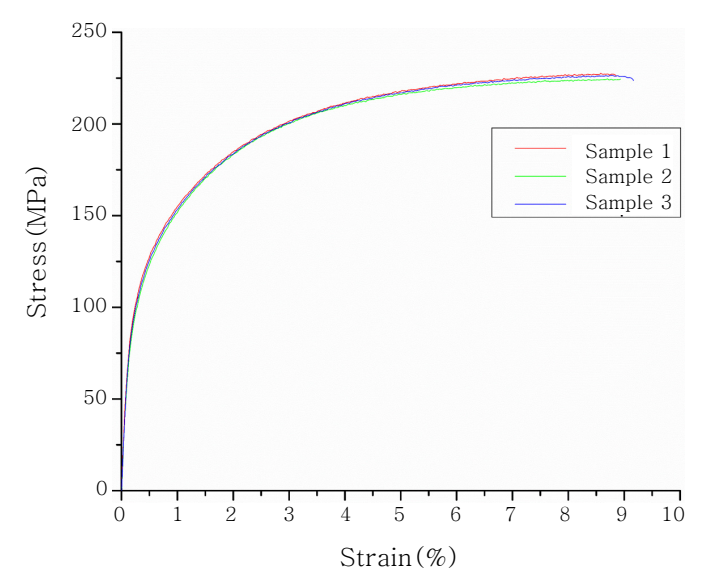

Fig. 5 As-deposited Al-Si block stress strain curves

Table 2 LMD optimized parameters

\begin{tabular}{|l|c|c|}
\hline & $\begin{array}{c}\text { Block } \\
\text { deposition }\end{array}$ & $\begin{array}{c}\text { Single wall } \\
\text { deposition }\end{array}$ \\
\hline Laser power (watt) & 900 & $900^{*}$ \\
\hline Powder feed rate $(\mathrm{g} / \mathrm{min})$ & 3.5 & 6.3 \\
\hline Scanning speed $(\mathrm{mm} / \mathrm{min})$ & 720 & 576 \\
\hline
\end{tabular}

*50 watts Laser power subsequently decreased every $5 \mathrm{~mm}$ until 800 watt laser powder was achieved. perpendicular to previous deposited layer and hence the transverse layer shows no overlapping beads. The microstructure of transverse section of deposited block shows that coarse columnar dendrites gradually transformed to fine equiaxed dendrites around middle of each layer. Silicon particles is the brighter phase and darker phase is the $\alpha$-aluminum dendrites. Since the bead boundary area is the liquid/solid interface and due to high thermal gradient and low solidification velocity at the lower part of the melt pool, columnar dendrites are formed above the bead boundary opposite to the direction of heat flows. In Fig. $6 \mathrm{~b}$, it was found that the secondary inter-dendritic arms spacing on an average was about $2.4 \mu \mathrm{m}$. There were no major defects observed after deposition like de-bonding, cracks at layer interfaces. In Fig. 6c, the observed voids are the result of fallout of the Si particles while polishing the samples. High solidification velocity and low thermal gradient at upper part of the melt pool resulted in equiaxed microstructure as shown in Fig. 6d. Low hardness value of $70 \mathrm{HV}$ was observed just above the bead boundary due to the presence of coarse dendrites. Present results indicate a high value of hardness of $90 \mathrm{HV}$ at the upper part of each deposited layer due to the fine equiaxed microstructure. Dinda et al. reported 10 percent variation in hardness value while depositing Al-Si alloy with $\mathrm{CO}_{2}$ laser ${ }^{17}$. Current study with diode laser shows variation of about 28 percent in hardness value from the soft bead boundary area to the upper part of each layer of deposit.
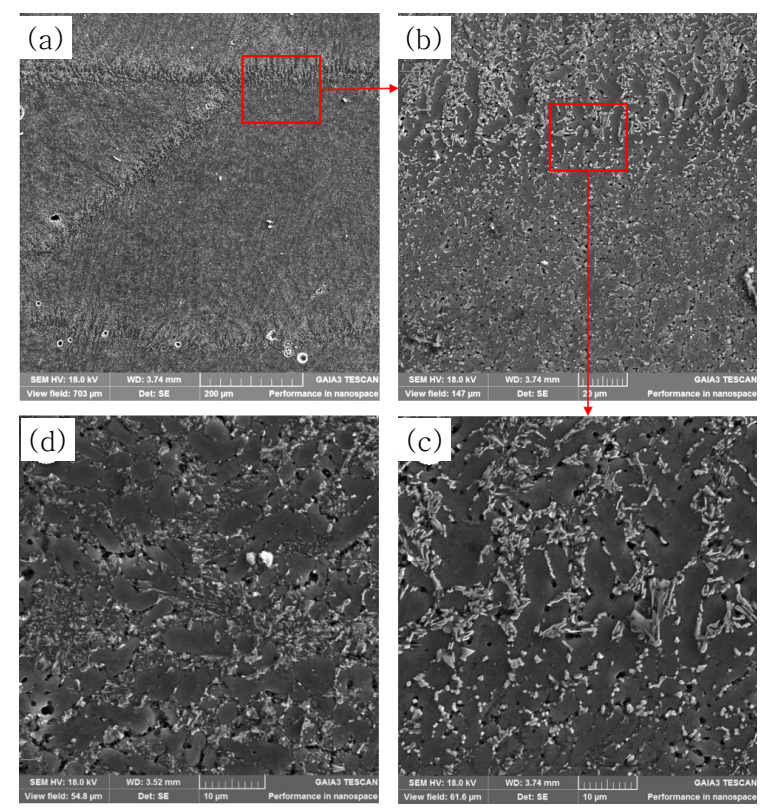

Fig. 6 (a, b, c) SEM micrographs of as-deposited block showing columnar dendrites above the bead boundary, (d) Top part of sample showing equiaxed microstructure 


\subsection{Single wall deposition}

LMD parameters were optimized for depositing single wall, as the parameters are dependent on material type and design requirements. Table 2 shows the optimized parameters for deposited single wall sample. Single wall was deposited using scanning pattern as shown in Fig. 4b. The first objective was to deposit defect free single wall sample with high deposition rate so that the welded bracket could be replicated with LMD bracket. LMD bracket has to be deposited high enough to replicate the welded bracket. Single wall deposit sample was deposited on the Al-6061 rolled plate before printing bracket on shock tower hood. Building single wall structure was a challenging process with aluminum alloys, because Aluminum alloys have high thermal conductivity. High laser power makes the single wall sample hot enough so that loose powder falling on the sides gets sintered and hinders the further deposition process. To overcome this challenge, laser power had to be reduced after every $5 \mathrm{~mm}$ while maintaining continuous melt pool. This sintering issue was hurdle to achieve height more than 15 $\mathrm{mm}$. The top surface of the wall at the end of the deposition was found to be wavy in nature and not flat. Waviness might be due to unstable melt pool and high thermal conductivity of Al alloy. Single wall sample was deposited on three different substrate having thick-

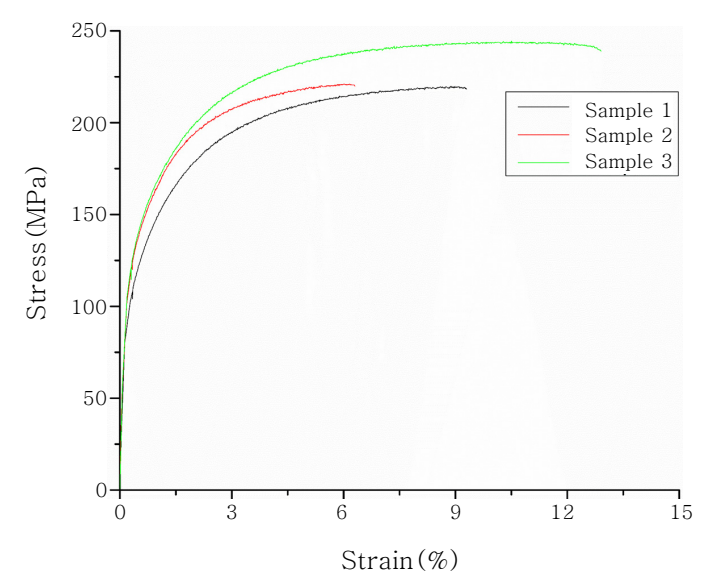

Fig. 7 As-deposited Al-Si single wall tensile samples stress strain curves

Table 3 Mechanical properties of as-deposited Al-Si alloy

\begin{tabular}{|l|c|c|}
\hline & $\begin{array}{c}\text { Block } \\
\text { deposition }\end{array}$ & $\begin{array}{c}\text { Single wall } \\
\text { deposition }\end{array}$ \\
\hline Yield strength (MPa) & 122.43 & 105.43 \\
\hline Ultimate tensile strength (MPa) & 225.71 & 225.6 \\
\hline Elongation (\%) & 9.0 & 9.4 \\
\hline
\end{tabular}

ness of $1.5 \mathrm{~mm}, 2.0 \mathrm{~mm}$, and $3.0 \mathrm{~mm}$ to conduct substrate thickness test . This test revealed that minimum 2 $\mathrm{mm}$ thick substrate was required to avoid distortion in the substrate. Note that the shock tower hood thickness was about $3 \mathrm{~mm}$, hence, same process parameters was used to build single wall bracket on the shock tower hood. Before printing on the shock tower, last step was to analyze the mechanical properties to test the feasibility for practical implementation.

The tensile test of single wall sample exhibited average $225 \mathrm{MPa}$ ultimate tensile strength with average elongation of $9.4 \%$. Though the average UTS and elongation was found to be same as of block deposited sample but in case of single wall tensile test sample, there is maximum variation of $50 \%$ in elongation and $9 \%$ variation in UTS. Tensile test results shows that mechanical properties are at par with the conventional cast counterparts. After conclusive tests, single wall was printed on shock tower hood as shown in Fig. 10 with optimized parameters. No deformity was observed after printing on shock tower hood, only minor impression was located right at bottom of deposition.

The continuous columnar dendrites were observed as shown in Fig. 8a and no circular bead boundary was spotted because the sample for the microscopy of single wall was cut perpendicular to scanning direction. Fig. $4 \mathrm{~d}$ exhibited the epitaxial growth of $\alpha-\mathrm{Al}$ dendrites over successive layers due to directional heat flow towards the substrate. The gray primary dendrites is the $\alpha$ - alu-
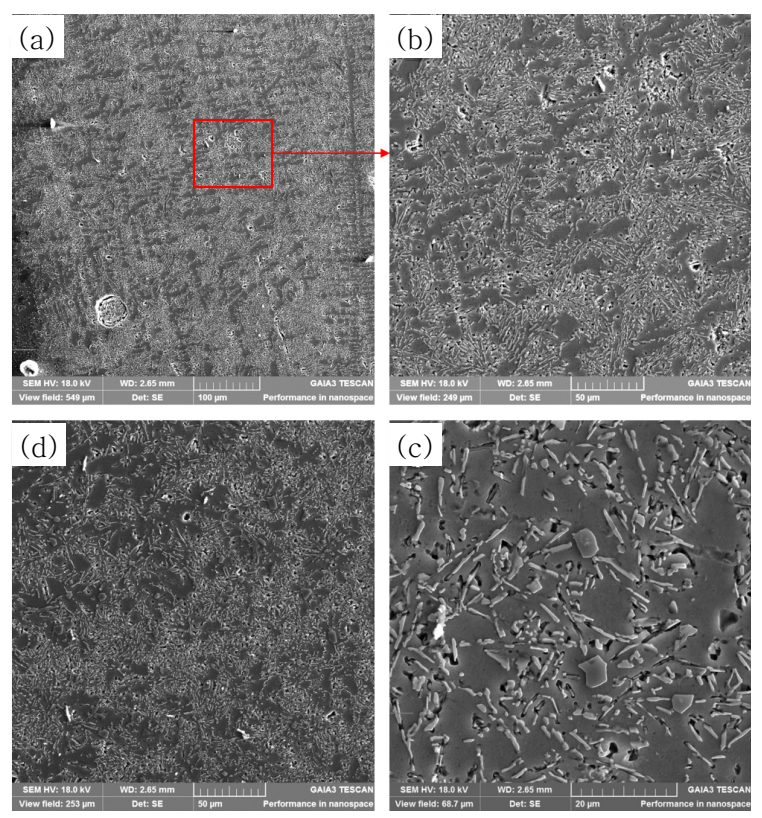

Fig. 8 Single wall deposit micrographs showing (a) Overview of dendritic structure, (b) Zoomed view around columnar dendrite, (c) Zoomed view at height of $15 \mathrm{~mm}$, and (d) Top of single wall 


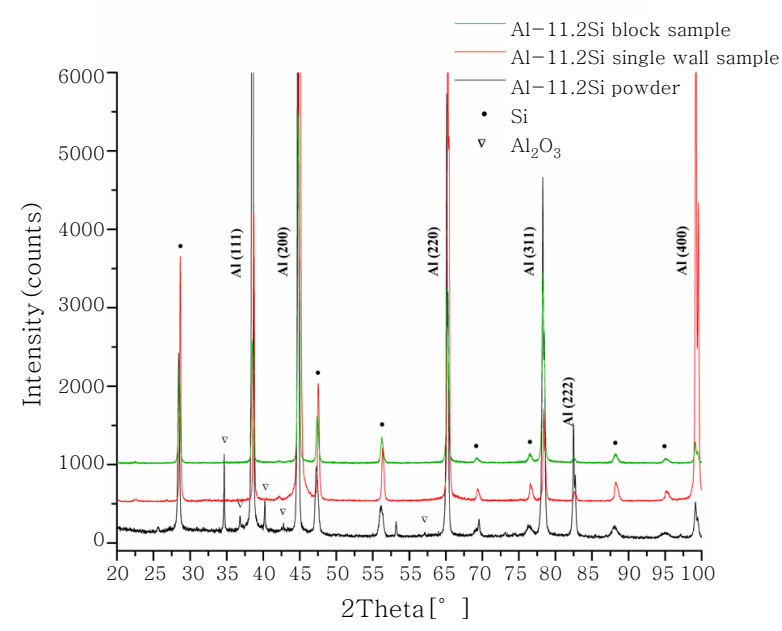

Fig. 9 XRD plots of Al-11.2 powder, single wall sample, and block sample

minum and bright constituents represents the silicon particles.

Inter dendritic region has eutectic structure as shown in Fig. 8b. Polygonal shaped silicon particles were observed just below the solid/liquid interface due to coarsening of fibrous eutectic Si particles because of secondary heating during subsequent layer deposition as shown in Fig. 8c.

Since the top part of top layer was not re-melted, therefore top part of single wall deposit exhibited equiaxed structure as shown in Fig. 8d due to low thermal gradient and high solidification velocity. The microhardness test of single wall sample revealed average microhardness of about $76.71 \mathrm{HV}$. Top part with equiaxed microstructure had the highest microhardness value of $82.13 \mathrm{HV}$ and rest of the deposit exhibited about $74 \mathrm{HV}$. XRD investigation revealed that $\alpha-\mathrm{Al}$ and Si phase exist in powder, single wall and block deposition. Oxidized $\mathrm{Al}$ was observed in as-received Al-11.2Si alloy powder as shown in Fig. 9. The lattice parameter for $\alpha$-Al calculated using Braggs law found to be $0.404 \mathrm{~nm}$ for both single wall and block deposition. Si peaks were higher in case of single wall sample depicting the presence of coarser Si particles than in block deposit. Final deposition on shock tower hood shown in Fig. 10.

\section{Conclusion}

Current study revealed that direct laser metal deposition process can be applied successfully to manufacture bracket on cast shock tower hood. As compared to conventional way of making parts separately and spot welding on shock tower hood, current method saves time and expenses. It further gives freedom for sophisticated

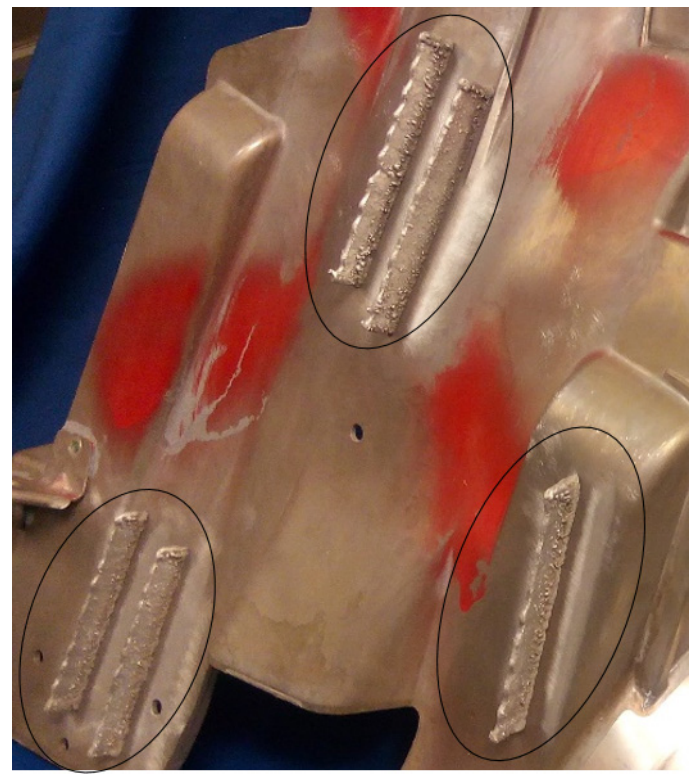

Fig. 10 Single wall Al-Si deposits on shock tower hood

designs. In both cases of block and single wall deposition, tensile tests exhibited excellent combination of 225 MPa UTS and $9 \%$ elongation. Effect of reducing laser power in case of single wall deposit resulted in defect free deposition until $15 \mathrm{~mm}$. Laser Power cannot be decreased after 800 watt as more reduction would create unstable melt pool, which would disrupt the further deposit growth and can cause major defects. Average microhardness of block deposition and single wall deposition was exhibited almost same hardness difference of about $3 \mathrm{HV}$ from bottom to top of the deposits. Density of deposits was greater than $99.9 \%$ in both cases. Bottom part of each layer exhibited columnar microstructure due to the high thermal gradient and low solidification velocity in both deposit. In contrast, top of each layer exhibited equiaxed dendritic structure due to low thermal gradient and high solidification velocity at the upper part of melt pool.

\section{Acknowledgement}

The authors are indebted to Venkata Surya Kartik, Karthik Alagarsamy, Rohan Sharma, Peter Christian for their valuable input.

\section{References}

1. Chou, R., J. Milligan, M. Paliwal, and M. Brochu, Additive Manufacturing of Al-12Si Alloy Via Pulsed Selective Laser Melting, Jom, 67(3) (2015), 590-596

2. Dinda, G.P., A.K. Dasgupta, and J. Mazumder, Evolution of microstructure in laser deposited $\mathrm{Al}-11.28 \% \mathrm{Si}$ alloy, Surface and Coatings Technology, 206(8-9) (2012), 2152- 
2160

3. Nahmany, M., I. Rosenthal, I. Benishti, N. Frage, and A. Stern, Electron beam welding of AlSi10Mg workpieces produced by selected laser melting additive manufacturing technology, Additive Manufacturing, 8(2015), 63-70

4. Olatunde Olakanmi, E., K.W. Dalgarno, and R.F. Cochrane, Laser sintering of blended Al-Si powders, Rapid Prototyping Journal, 18(2) (2012), 109-119

5. Wang, X.J., L.C. Zhang, M.H. Fang, and T.B. Sercombe, The effect of atmosphere on the structure and properties of a selective laser melted $\mathrm{Al}-12 \mathrm{Si}$ alloy, Materials Science and Engineering, A, 597 (2014), 370-375

6. Thijs, L., K. Kempen, J.-P. Kruth, and J. Van Humbeeck, Fine-structured aluminium products with controllable texture by selective laser melting of pre-alloyed AlSi10Mg powder, Acta Materialia, 61(5) (2013), 1809-1819

7. Dinda, G.P., A.K. Dasgupta, and J. Mazumder, Laser aided direct metal deposition of Inconel 625 superalloy, Microstructural evolution and thermal stability, Materials Science and Engineering A, 509(1-2) (2009), 98-104

8. Dinda, G.P., L. Song, and J. Mazumder, Fabrication of Ti-6Al-4V scaffolds by direct metal deposition, Metallurgical and Materials Transactions A, Physical Metallurgy and Materials Science, 39(12) (2008), 2914-2922

9. Mazumder, J., J. Choi, K. Nagarathnam, J. Koch, and D. Hetzner, The direct metal deposition of H13 tool steel for 3-D components, JOM, (1997), 49(5), 55-60

10. Mazumder, J., D. Dutta, N. Kikuchi, and A. Ghosh, Closed loop direct metal deposition, Art to Part, Optics and Lasers in Engineering, 34(4-6) (2000), 397-414
11. Zhuang, W., Q. Liu, R. Djugum, P.K. Sharp, and A. Paradowska, Deep surface rolling for fatigue life enhancement of laser clad aircraft aluminium alloy, Applied Surface Science, 320 (2014), 558-562

12. Kang, N., P. Coddet, L. Dembinski, H. Liao, and C. Coddet, Microstructure and strength analysis of eutectic Al-Si alloy in-situ manufactured using selective laser melting from elemental powder mixture, Journal of Alloys and Compounds, 691 (2017), 316-322

13. Prashanth, K.G., S. Scudino, and J. Eckert, Defining the tensile properties of Al-12Si parts produced by selective laser melting, Acta Materialia, 126(2017), 25-35

14. Li, X.P., X.J. Wang, M. Saunders, A. Suvorova, L.C. Zhang, Y.J. Liu, M.H. Fang, Z.H. Huang, and T.B. Sercombe, A selective laser melting and solution heat treatment refined Al-12Si alloy with a controllable ultrafine eutectic microstructure and $25 \%$ tensile ductility, Acta Materialia, 95 (2015), 74-82

15. Mathew, R., P.R. Stoddart, D. Nolan, and Y. Durandet, Microstructural refinement of aluminium-zinc-silicon coated steels, Surface and Coatings Technology, (2016)

16. Simchi, A., Direct laser sintering of metal powders, Mechanism, kinetics and microstructural features, Materials Science and Engineering, A, 428(1-2) (2006), 148-158

17. Dinda, G.P., A.K. Dasgupta, S. Bhattacharya, H. Natu, B. Dutta, and J. Mazumder, Microstructural Characterization of Laser-Deposited Al 4047 Alloy, Metallurgical and Materials Transactions A, 44(5) (2012), 2233-2242 